Artigo recebido em

29/07/2014

Aprovado em

$27 / 10 / 2014$

Cristiane Finger

Pontifícia Universidade

Católica do Rio Grande

do Sul

Profa. Dra. PPGCOM da Famecos/PUCRS -Televisão e Telejornalismo

MARIANA OSELAME

UNIRITTER

Profa. Me. Curso de Jornalismo
Estudos em Jornalismo e Mídia

Vol. 11 No 2 Julho a Dezembro de 2014

ISSNe 1984-6924

\section{Futebolização do Esporte na Televisão: compromisso com o jornalismo ou com os números de audiência?}

\author{
Cristiane Finger e Mariana Oselame
}

\section{Resumo}

Este artigo aborda a cobertura esportiva da televisão aberta brasileira. Os objetivos são mensurar a predominância dos conteúdos de futebol em relação aos de outros esportes; evidenciar a utilização do "engraçadismo" no tratamento das informações esportivas no contexto do infoentretenimento; e discutir se o amplo espaço destinado ao futebol é resultado da aplicação de critérios jornalísticos ou se é fruto da pressão por bons números de audiência. $\mathrm{O}$ corpus analisado inclui as versões gaúcha e paulista do programa Globo Esporte, exibido pela Rede Globo e por suas emissoras afiliadas. A argumentação teórica desta abordagem tem como base os conceitos de Alcoba (1999), Traquina (2008), Wolf (1985) e Rangel (2006).

Palavras-chave

Televisão; Jornalismo Esportivo; Infoentretenimento.

\begin{abstract}
This article discusses sports coverage of the Brazilian broadcast television. The objectives are measuring the supremacy of football's content in relation to other sports; highlighting the prevalence of "engraçadismo" in the treatment of sports information; and discuss if the ample space dedicated to the football is a result of the journalistic criteria or of the pr-essure by good audience numbers. The corpus is formed by the Rio Grande do Sul and São Paulo versions of Globo Esporte produced by Rede Globo and its affiliated stations. The theoretical argument is based on the concepts of Alcoba (1999), Traquina (2008), Wolf (1985) and Rangel (2006).
\end{abstract}

Keywords

Television; Sports Journalism; Infotainment. 


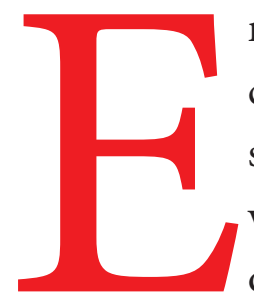

$\mathrm{m}$ que pese o consumo dos conteúdos relacionados ao segmento esportivo é possível afirmar que não há meio de comunicação mais popular no Brasil do que a televisão. É por meio dela que a maioria dos brasileiros $-72 \%$, segundo a pesquisa Esporte Clube Ibope Media, de 2011 - busca as informações sobre os clubes, os times, os campeonatos, os atletas e os megaeventos esportivos como a Copa do Mundo de futebol e os Jogos Olímpicos. Esse percentual, relevante no contexto dos meios de comunicação, é quase quatro vezes maior do que a preferência pelo rádio $\mathrm{AM}$ e $\mathrm{FM}$ - companheiro frequente dos torcedores nos estádios e citado por $21 \%$ dos entrevistados como a principal fonte de informação sobre a área esportiva.

Entre as explicações possíveis para essa preferência pela televisão estão as características desse meio de comunicação. Enquanto som e imagem - diferentemente do rádio, que é apenas som - a televisão tem o poder de seduzir, atrair, conquistar, mobilizar e sensibilizar. De acordo com Ferrés (1998, p. 89), "a televisão representa o triunfo da cultura da sedução, da cultura do desejo, não apenas porque é o principal motor na fabricação de desejos, como também porque ela mesma é expoente do desejo". Não é sem motivo que as vendas de aparelhos de televisão disparam às vésperas de torneios esportivos importantes notadamente a Copa do Mundo de futebol.

1-PLURI CONSULTORIA. O PIB do Esporte Brasileiro. 2012. Disponível em: <http://www. pluriconsultoria. com.br/uploads/ relatorios/PIB\%20 Esporte.pdf>. Acesso em: nov. 2012.
Em 2014, por exemplo, conforme dados apurados pelo instituto GfK (apud Meio e Mensagem, 2014), as vendas de televisores registraram, em maio, um crescimento semanal acima de $60 \%$ na comparação com o mesmo período de 2013.

Ver uma partida de futebol na televisão é completamente diferente do que apenas ouvi-la no rádio; por meio da imagem é possível criar e reforçar estereótipos. Além disso, também é possível potencializar o alcance das marcas. Futebol e televisão, aliás, formam uma parceria interessante em termos de possibilidades de negócios no âmbito publicitário. De um lado está um veículo capaz de atingir a totalidade do território brasileiro e com o poder de comprar os milionários direitos de transmissão que, em última instância, viabilizam a existência dos megaeventos esportivos; de outro, está um esporte que movimenta milhões de reais dentro e fora de campo e que desperta muito o interesse de uma grande parte da audiência da televisão.

O cenário atual é favorável a essa parceria e ao esporte de modo geral. A indústria do esporte encontrou no Brasil um terreno fértil para prosperar desde que o país foi eleito para receber os maiores eventos esportivos do planeta: a Copa do Mundo, em 2014, e os Jogos Olímpicos, em 2016. Segundo Graça e Kasznar (2012), entre 2000 e 2010, quando o país cresceu 3,2\%, a taxa média de evolução do PIB gerado pela atividade esportiva foi de $6,2 \%$. Segundo eles, o setor movimentou em torno de $\mathrm{R} \$$ 78,6 milhões somente em 2010. Esse valor, conforme a Pluri Consultoria ${ }^{1}$, equivale a $1,6 \%$ do PIB nacional e revela um dado importante: "a economia brasileira anda no ritmo europeu, o esporte, em um ritmo chinês".

Por essas características é possível afirmar que a televisão é o veículo por excelência da editoria de esportes que, em teoria, se dedica a divulgar todas as manifestações esportivas. "Em teoria", porque, mesmo que tenha a denominação genérica de "esportes", esse segmento, na prática (e especialmente na televisão), é amplamente do- 
minado pelo futebol, como foi explicitado anteriormente. Conforme o Ibope (2011), esse é o conteúdo mais consumido em todas as plataformas midiáticas. Na televisão ele é acompanhado por $92 \%$ da audiência - um público muito superior aos $24 \%$ que assistem às competições de vôlei, segunda modalidade mais consumida nesse meio de comunicação. Os outros dois esportes lembrados na pesquisa - o automobilis$\mathrm{mo}^{2}$ e o basquete - representam, respectivamente, $13 \%$ e $10 \%$ da preferência.

\section{Muito futebol, pouco esporte}

Essa supremacia pode ser analisada por diferentes ângulos. Para alguns teóricos como Erbolato (1981), uma das características do jornalismo especializado - em particular do jornalismo esportivo - é a possibilidade da amplitude da cobertura. "Aplicando-se as regras gerais sobre entrevista, reportagem, redação e diagramação, pode uma seção esportiva abordar aspectos variadíssimos, dependendo da orientação da editoria e da produção" (ERBOLATO, 1981, p. 14). Assim, um olhar mais ampliado sobre todas as manifestações esportivas, independentemente do interesse da audiência por elas, ofereceria uma cobertura mais vasta, mais diversificada. Já um olhar menos amplo, direcionado a apenas um esporte, restringiria o conteúdo. Mesmo uma cobertura mais focada em uma modalidade poderia se mostrar diversificada se, por exemplo, como afirma Coelho (2008), os critérios jornalísticos de seleção de pauta e construção da notícia fossem utilizados com mais frequência nas redações:

É possível fazer uma brilhante matéria de economia falando de futebol. A crise do Flamengo, incapaz de saldar dívidas e de manter seu orçamento no azul há mais de dez anos, pode render peça jornalística primorosa e repleta de realidade sobre a administração dos clubes do país. A maneira como os campeonatos do Brasil são organizados, sempre levando em conta algum acordo político (...), poderia valer um prêmio Esso de cobertura política. (COELHO, 2008, p. 22-23).

A importância conferida ao futebol e o grande espaço ocupado por esse esporte também podem ser interpretados como uma expressão dos elementos do sensacionalismo tão presente nos meios de comunicação neste início de século XXI. É o que afirma Aurora Bernal, em Periodismo Deportivo y Sensacionalismo: Motivos para la Reflexión, tendo como pano de fundo o excessivo espaço dedicado ao futebol na cobertura esportiva da imprensa espanhola:

Sería interesante proceder a una medición sobre el tanto por ciento que el fútbol ocupa en los medios de comunicación (...). Este interés está basado en la existencia del fútbol como deporte de masas y masas significa audiencia, público, y, por tanto, interés publicitario. Además de interés por los derechos futbolísticos en la televisión ${ }^{3}$. (BERNAL, apud MONTÍN, 2008, p. 165).

Essa medição a que Bernal se refere já foi feita por Antonio Alcoba, principal referência na pesquisa acadêmica sobre o campo do jornalismo esportivo. Em Deporte y Comunicación (1984), o espanhol ressalta que $90 \%$ do noticiário esportivo de países como a Espanha e o Brasil são dedicados aos resultados dos campeonatos de futebol. Em outro estudo, La Prensa Deportiva (1999, p. 26), ele afirma que os diários esportivos deveriam ser "un mosaico de la actualidad deportiva general, otorgando, obviamente, mayor importancia y espacio a aquellas áreas más seguidas por los lectores y a acontecimientos en los
2- Esses 13\% que preferem o automobilismo destacaram uma categoria em especial: a Fórmula 1, modalidade em que o Brasil já alcançou destaque internacional e que há mais de quatro décadas é transmitida pela Rede Globo.

3- "Seria interessante fazer uma medição sobre o espaço ocupado pelo futebol nos meios de comunicação (...). Esse interesse está baseado na visão do futebol como um esporte de massas; e massas significam audiência, público e, portanto, interesse publicitário. Além dos interesses pelos direitos de transmissão do futebol na televisão" (tradução livre). 
que se encuentran inmersos deportistas nacionales o locales ${ }^{4}$. O pensamento de Alcoba se refere aos diários esportivos impressos, mas pode, também, ser aplicado à televisão. Os programas esportivos de televisão, assim como os jornais impressos, deveriam ser um mosaico de atualidades esportivas - sempre enfatizando, claro, as notícias mais relevantes da cobertura dessa editoria, decididas por meio da observação e aplicação de valores-notícia e critérios de noticiabilidade.

\section{Jornalismo esportivo é jornalismo}

Mas como hierarquizar as notícias? Que critérios de noticiabilidade aplicar no campo do jornalismo esportivo? Partindo do pressuposto de que "jornalismo é jornalismo, seja ele esportivo, político, econômico, social" (BARBEIRO e RANGEL, 2006, p.13), os critérios de noticiabilidade aplicáveis à editoria de esportes são os mesmos utilizados pelos jornalistas de outras áreas. Afinal, como prosseguem os autores, "a essência não muda porque sua natureza (do jornalismo) é única e está intimamente ligada às regras da ética e ao interesse público". E, por interesse público, expressão que remete à ideia de "bem comum", entende-se os "bens imateriais indivisíveis, que pertencem a todos, ou seja, a uma totalidade dos unidos por valores-verdades em que acreditam" (BOBBIO, MATTEUCCI e PASQUINO apud CHAPARRO, 2012). Oriundo da Ciência Políti-

4- "(...) um mosaico da atualidade esportiva geral, dando, obviamente, maior importância e espaço para as áreas mais lidas e para os acontecimentos envolvendo os atletas nacionais e locais" (tradução livre). ca, o conceito se refere aos valores concretos, como pátria e família, e aos abstratos, como igualdade, liberdade e honra. De acordo com Chaparro (2012), cabe ao jornalismo observar o interesse público em todas as suas instâncias - nunca cedendo ao interesse do público, entendido como "o que as audiências querem ver".
Nesse sentido, é fundamental observar, no dia-a-dia do jornalismo esportivo, os critérios de noticiabilidade elencados por autores como Traquina (2008) e Wolf (1985), entre eles a notabilidade, a novidade, a personalização, a significância, o entretenimento e a humanidade. Prega a prática jornalística que todo acontecimento deve ser observado pelo profissional por meio dos "óculos" dos valores-notícia (TRAQUINA, 2008). Nesse processo, fatos que não reúnam as condições necessárias para ser transformados em notícia devem ser descartados. Cabe ao jornalista esportivo, portanto, avaliar corretamente os acontecimentos para que as notícias veiculadas sejam o resultado de um processo de seleção dos fatos mais importantes.

Afinal, não é porque o jornalismo esportivo se ocupa de um assunto que é visto como entretenimento por muitos telespectadores, leitores e ouvintes que ele deve abrir mão dos princípios da profissão - entre eles o interesse público, o dever de informar corretamente, de apurar os fatos, de narrar os acontecimentos conforme a ética e a deontologia do fazer jornalístico. É preciso reconhecer, porém, que às vezes isso acontece. É como se os "óculos" do jornalista esportivo ficassem "embaçados", impedindo o profissional de avaliar os fatos corretamente. Nesse caso, geralmente, os valores-notícia são desvirtuados em nome da audiência e da necessidade de vender um determinado produto/evento esportivo na televisão.

É nesse contexto que entra em cena o "engraçadismo", um recurso amplamente utilizado pelos jornalistas esportivos na tentativa de "universalizar" a cobertura de esportes e atingir públicos que, em princípio, não teriam interesse nesse assunto. O conceito, desenvolvido na dissertação 
de Mestrado intitulada Fim da Notícia: o Engraçadismo no Campo do Jornalismo Esportivo de Televisão (OSELAME, 2013), se refere principalmente à utilização exagerada do humor nas reportagens esportivas. $\mathrm{O}$ excesso de brincadeiras no texto jornalístico que deveria ser objetivo; a vasta utilização de expressões com duplo sentido quando a missão do jornalista é ser o mais claro possível; o predomínio do infoentretenimento sobre o jornalismo, principalmente na escolha das pautas: são essas as principais características deste fenômeno identificado por meio da análise do mesmo objeto de estudo deste artigo, o programa Globo Esporte, da Rede Globo. No desenvolvimento do conceito, observou-se que "o programa assume a postura de que é mais importante provocar o riso, entreter e descontrair do que, propriamente, informar" (OSELAME, 2013, p. 18). Dessa forma, segundo a lógica do "engraçadismo", o esporte poderia interessar um público ainda maior - gerando melhores números de audiência e, por consequência, mais retorno financeiro.

A prática do "engraçadismo" tem como pano de fundo o infoentretenimento como tendência do jornalismo neste início de século (GOMES, 2011). Tendência essa que, por sua vez, segundo Patias (2006, p. 92), nada mais é do que "uma mistura de informação e entretenimento que produz espetáculo". Também é possível afirmar que o infoentretenimento é um dos resultados do processo ao qual Rangel se refere como a hibridização dos gêneros:

$\mathrm{Na}$ contemporaneidade, a informação deixa de significar a representação simbólica dos fatos para se apresentar como produto híbrido que se associa ora à publicidade, ora ao entretenimento, ora ao consumo; mas muitas vezes deixando de cumprir a sua missão primordial de informar [grifo nosso]. (RANGEL, 2010, p. 3).

Assim, conforme observado na dissertação anteriormente citada, a função essencial do jornalista já não é mais selecionar, tratar e apresentar as notícias em um pacote ao mesmo tempo atraente e informativo, mas, antes disso, divertir. Privilegiando a piada em detrimento da informação, o jornalista acaba sendo uma espécie de humorista nesse espetáculo esportivo.

\section{Esporte como espetáculo}

Em razão do envolvimento das emissoras de televisão não apenas na transmissão dos eventos esportivos como na sua promoção - e devido a práticas como o "engraçadismo" que se desenvolve no contexto do infoentretenimento -, muitas vezes torna-se difícil pensar em princípios éticos e, principalmente, distinguir a tênue fronteira entre o jornalismo esportivo e o espetáculo. Para Coelho (2008), não raro a informação esportiva fica em segundo plano diante da necessidade de se promover o show - afinal, enquanto produto, ele nada mais é do que um alto investimento que precisa gerar uma contrapartida. Nesse cenário, o futebol, esporte que a maior parte do público quer ver na televisão, é infinitamente mais lucrativo do que as demais modalidades esportivas, que encontram um público menor nos canais abertos.

No intuito de promover esse show, é como se os jornalistas contassem com uma espécie de "licença" para ignorar princípios básicos do jornalismo como, por exemplo, o compromisso com a verdade dos fatos. “(...) el profesional del periodismo tiene licencia para gritar y vociferar durante una retransmisión, para animar a los deportistas, para dejarse llevar por las emociones 
5- "O jornalista tem licença para gritar durante uma transmissão esportiva para animar os atletas. Ele pode se deixar levar pelas emoções (até a rouquidão) ou, inclusive, pela paixão por uma das cores" (tradução livre). 6- Apenas a TV Globo de São Paulo produzia e exibia na íntegra uma versão local do programa. As demais emissoras e praças exibiam a versão do Rio de Janeiro na qual inseriam apenas um bloco com as notícias locais. 7- Expressão utilizada para se referir ao tempo de produção de um programa de televisão. 8- Matérias "recomendadas" são aquelas reportagens com conotação comercial. As mais comuns são as que repercutem um produto esportivo cujos direitos de transmissão são exclusivos da Rede Globo como, por exemplo, o Campeonato Mundial de Fórmula 1, a Stock Car, a Superliga de Vôlei, entre outras competições. (hasta la ronquera o el paroxismo) o incluso por la afición a unos colores" (LORA apud MONTÍN, 2008, p. 59). Para Eugênio Bucci (2004, p. 191), nesse processo de associação e copromoção das competições, as emissoras "não fazem mais a cobertura dos fatos, mas, comprando a exclusividade de transmissão, transformam seus locutores em animadores dos eventos". Dessa forma, a objetividade, a precisão e o rigor na aplicação dos critérios de noticiabilidade deram lugar à preferência pelos chamados fatos omnibus conceituados por Bourdieu; aqueles eventos que "não envolvem disputa, não dividem, que formam consenso, que interessam a todo mundo, mas de um modo tal que não tocam em nada importante" (1997, p. 23). A espetacularização passou a ser o principal atributo dos acontecimentos na escolha das notícias em potencial. O objetivo já não é apurar e divulgar as notícias de acordo com os critérios de noticiabilidade, mas sim entreter o telespectador e angariar bons números de audiência - meta que não é atingida com a exibição de conteúdos menos "atraentes" para o público como, por exemplo, as modalidades olímpicas.

\section{Globo Esporte}

No cenário dos programas esportivos da televisão aberta brasileira, o Globo Esporte, exibido pela Rede Globo e suas afiliadas, é o mais tradicional. No ar desde 14 de agosto de 1978, a atração começou como um programa jornalístico de esportes com a apresentação de Léo Batista. As notícias eram transmitidas de modo formal; as matérias eram marcadas pela objetividade. Um dos blocos do programa era dedicado às informações locais das afiliadas ${ }^{6}$.

A primeira grande reformulação do Globo Esporte veio em 2001; uma segunda repaginação aconteceu em 2008, quando a atração se tornou um programa de esportes de caráter nacional. A iniciativa não funcionou - o formato era nacional demais para um assunto com tantas especificidades locais - e a emissora decidiu promover novas mudanças em 2009. Dessa vez foi adotada uma linguagem que vinha sendo testada no Globo Esporte de São Paulo. Quando assumiu o programa, o jornalista Tiago Leifert aboliu o teleprompter e substituiu o tom formal de apresentação por uma nova linguagem, mais solta e mais próxima dos telespectadores. "Antes parecia que era tudo muito ensaiadinho, combinado e acertado, e agora a gente tenta de tudo para que seja espontâneo, porque todos os repórteres sabem do que estão falando, não precisa ser ensaiado", justificou (LEIFERT apud RANGEL, 2008, p. 4).

Satisfeita com a audiência e com os bons resultados obtidos em São Paulo, a Globo optou por repetir a fórmula de uma edição regional em outros sete estados brasileiros: Rio Grande do Sul, Santa Catarina, Paraná, Minas Gerais, Bahia, Pernambuco e Ceará. Em 16 de maio de 2011, essas emissoras passaram a produzir as suas próprias edições do programa com relativa autonomia. Para preencher o fade ${ }^{7}$ diariamente, as praças ganharam o apoio da Agência Globo Esporte, criada nesse mesmo período com o objetivo de distribuir os conteúdos de abrangência nacional e as matérias "recomendadas ${ }^{8 "}$ pela chefia geral do programa aos editores-chefes regionais. Os demais estados continuaram assistindo à versão do Globo Esporte que é produzida e transmitida ao vivo do Rio de Janeiro; também seguiram veiculando um bloco local com as informações dos seus campeonatos e atletas regionais. 


\section{Pré-Análise}

Metodologia aplicada neste estudo, a análise de conteúdo sistematiza por Bardin (1977) se estrutura em torno de três polos: a pré-análise, que é a fase de organização da pesquisa; a exploração do material, referente à administração sistemática das decisões tomadas; e o tratamento dos resultados, que nada mais é do que a validação dos dados que foram obtidos.

$\mathrm{Na}$ fase de pré-análise, por meio de uma leitura flutuante, foi definido um corpus para ser submetido aos procedimentos analíticos. Foram selecionadas quatro edições do Globo Esporte São Paulo, precursor do atual formato do programa; e quatro edições do Globo Esporte Rio Grande do Sul, um dos estados que seguiu o modelo definido como ideal para a atração. Os oito programas foram gravados entre 13 de março e três de abril de 2012 - o período foi escolhido aleatoriamente. Essas edições foram levadas ao ar sempre às terças-feiras (13/03/2012, 20/03/2012, 27/03/2012 e 03/04/2012), entre $12 \mathrm{~h} 50 \mathrm{~min}$ e $13 \mathrm{~h} 20 \mathrm{~min}$, quando o noticiário ainda não foca a repercussão de partidas e nem a apresentação da rodada.

Foram utilizadas, para efeitos de classificação, duas unidades de registro: temática e abordagem. Para cada unidade de análise foram criadas duas categorias: para a unidade temática, as categorias Futebol e Outros, agrupando, respectivamente, conteúdos de futebol e de outros esportes; para abordagem, Jornalismo ou Infoentretenimento, conforme a presença/ ausência de valor-notícia. As unidades de registro e as categorias foram pensadas a partir dos objetivos deste estudo: mensurar a predominância dos conteúdos de futebol em relação aos outros esportes; evidenciar a prevalência do "engraçadismo" no tratamento das informações esportivas; e discutir se o amplo espaço destinado ao futebol é resultado da aplicação de critérios jornalísticos ou se é fruto da pressão pelos bons números de audiência.

\section{Exploração do material}

Encerrada a etapa de pré-análise, parte-se para a exploração do material correspondente ao primeiro objeto a ser pesquisado, o Globo Esporte São Paulo. De posse do tempo total ocupado pelas matérias, chamadas de bloco, entrevistas e segmentos de opinião do programa, o ponto de partida foi calcular o espaço ocupado pelas duas categorias da unidade de registro. De acordo com os dados obtidos, a versão paulista do programa dedicou $1 \mathrm{~h} 20 \mathrm{~min} 26 \mathrm{~s}$ do total analisado - 1h31min11s - para tratar de assuntos relacionados ao futebol - abordando com maior destaque os clubes da capital (São Paulo, Corinthians e Palmeiras). Somente 10min45s das edições que compõem o corpus desta pesquisa fizeram referência a outros esportes, principalmente ao vôlei, futsal, MMA (artes marciais mistas) e automobilismo. Em termos percentuais, a categoria Futebol englobou 88\% do corpus; a categoria $\mathrm{Ou}-$ tros ficou com $12 \%$.

Quanto à abordagem, 56min29s (62\%) se caracterizaram pela ausência de valores-notícia e, por isso, foram enquadrados como pertencentes à categoria Infoentretenimento. O restante $-34 \min 42 \mathrm{~s}(38 \%)$ - foi classificado como Jornalismo em razão da existência de valores-notícia e critérios de noticiabilidade como significância, conflito, infração, amplitude.

Resultados semelhantes também foram observados no Globo Esporte produzido e exibido no Rio Grande do Sul. Os assuntos relacionados ao futebol (com ênfase nos 
dois clubes de Porto Alegre, Grêmio e Internacional) ocuparam a maior parte das edições analisadas somando $1 \mathrm{~h} 16 \mathrm{~min} 25 \mathrm{~s}$ de um total de $1 \mathrm{~h} 31 \mathrm{~min} 02$; as outras modalidades esportivas (apareceram apenas o futsal, o basquete, o MMA, o tênis e o vôlei) responderam por apenas $14 \mathrm{~min} 37 \mathrm{~s}$. Percentualmente, a categoria Futebol respondeu por $84 \%$ do corpus analisado; $16 \%$ do Globo Esporte gaúcho foram dedicados à cobertura de outras modalidades esportivas.

No que se refere à abordagem, ao contrário da versão paulista do Globo Esporte, no programa produzido no Rio Grande do Sul houve uma predominância do Jornalismo sobre o Infoentretenimento. A categoria que contempla a presença da notícia somou 1 h01min (67\%) - o restante do corpus analisado, 30min02s (33\%), foi classificado como Infoentretenimento.

\section{Interpretação dos Dados}

9- Em 17 de julho de 2014, a revista Meio e Mensagem publicou uma matéria em sua edição online expondo dados do Painel Nacional de Televisão, uma medição do Ibope que mapeia o consumo das emissoras em todo ao país. De acordo com o texto, a Rede Globo alcançou uma média de 23,5 pontos de audiência no período da Copa do Mundo do Brasil, entre 12 de junho e 13 de julho de 2014 cada ponto equivale a 217.460 domicílios. Essa média foi $10 \%$ superior à registrada na Copa do Mundo da África do Sul, em 2010, e 37\% maior do que a média diária de audiência antes do evento esportivo. Em outras palavras, a Copa incrementou - e muito os números.
$\mathrm{Na}$ última fase da análise de conteúdo antes das considerações finais, conforme Bardin (1977, p. 101), o pesquisador está apto a "propor inferências ou adiantar interpretações a propósito dos objetivos previstos". Depois da categorização e da organização dos resultados, o analista traçar um amplo panorama sobre o objeto em questão. Nesta pesquisa, por meio da classificação dos conteúdos nas categorias propostas - Futebol e Outros; Jornalismo e Infoentretenimento - foi possível fazer algumas inferências.

Emissora líder no Brasil, referência na cobertura de eventos esportivos e proprietária dos milionários direitos de transmissão das principais competições nacionais e internacionais, a Rede Globo, enquanto empresa de comunicação inserida em um já reúne as informações necessárias para mercado que busca o lucro, considera o esporte, mais do que uma editoria do jornalismo, um excelente negócio. $\mathrm{E}$, devido à massiva audiência ${ }^{9}$ que é capaz de atrair, o futebol, neste contexto, é inegavelmente o "rei dos esportes", como afirma reiteradamente Alcoba (1999) ao longo de seus estudos. Futebol gera interesse; ele traz o público para a televisão. Em última análise, futebol é sinônimo de (grande) audiência. Como foi explicitado no início desta pesquisa, ele é acompanhado por $92 \%$ dos telespectadores que se interessam por esporte - e que formam um grupo altamente explorado pelo mercado publicitário. $\mathrm{Na}$ prática, funciona como uma engrenagem bem sincronizada: as emissoras desembolsam quantias milionárias para comprar direitos de transmissão com a certeza da audiência e da satisfatória comercialização de anúncios; para promover os eventos que adquirem, utilizam a estrutura do jornalismo esportivo que, não raras vezes, desconhece as fronteiras entre a prática jornalística e a valorização do espetáculo.

Assim, por ser a modalidade que mais atrai audiência - e, por consequência, garante o retorno financeiro do investimento realizado - o futebol ocupa quase a totalidade do espaço destinado ao esporte. As outras modalidades são ofuscadas e raramente aparecem. Mesmo os esportes que foram identificados no corpus deste estudo - vôlei, futsal, MMA e automobilismo no Globo Esporte São Paulo; vôlei, tênis, futsal, basquete e MMA na versão gaúcha do programa - não foram inseridos por acaso na atração. Vôlei, automobilismo e basquete ocupam o segundo, o terceiro e o quarto lugar, respectivamente, nas pesquisas sobre o que o público quer ver na televisão; são modalidades com o retorno de audiência garantido. 
Tal é a desproporcionalidade da cobertura esportiva da televisão aberta brasileira que, se fosse possível uma comparação com alguma outra área do jornalismo especializado como, por exemplo, a política, seria o mesmo que, guardadas as devidas proporções, as emissoras decidissem veicular apenas as notícias do Senado Federal, reduzindo ao máximo o espaço destinado à Câmara dos Deputados. Ora, não são as duas instâncias relevantes do ponto de vista do jornalismo político? Da mesma forma são relevantes - ou deveriam ser - todas as modalidades esportivas para o jornalismo esportivo. Caso contrário, ele poderia se chamar, desde já, jornalismo futebolístico - que é, na prática, o que fazem os meios de comunicação.

Mensurada a supremacia do futebol, foi feita a análise do tratamento conferido ao conteúdo esportivo. No Globo Esporte São Paulo observou-se uma clara tendência ao Infoentretenimento, com reportagens como a que mostrou os jogadores do Santos cantando no videokê da concentração. Com 2min16s de duração, o VT exibido no dia três de abril de 2012 começa assim: "Se a gente colocar todo mundo num ranking, realmente o Richarlyson é o melhor", prossegue Leifert enquanto, no sobe som $^{10}$, o jogador citado aparece cantando. Logo depois entra um efeito de edição com fotos do atleta empunhando um microfone e a inscrição "Richarlyson in concert ${ }^{11}$. "Ronaldo é bom", prossegue o texto, com mais um sobe som, desta vez para Ronaldo. "Hernanes...", continua o apresentador, “pelo amor de Deus!". Depois de um trecho do atleta citado cantando (pessimamente) em um fundo com borboletas e flores inserido na ilha de edição, Leifert prossegue. "Só que agora tivemos que abrir um buraco no fundo do ranking para acrescen- tarmos Neymar Júnior e Paulo Henrique Ganso".

Novo efeito de edição, desta vez com os dois atletas, representados por caricaturas, cantando. Antes da imagem e do sobe som dos dois jogadores, o apresentador diz: “Misericórdia!". Após alguns segundos de desafinação da dupla, Leifert brinca. "Demoramos três minutos para descobrir que era uma música do Exaltasamba”. Mais um sobe som e um comentário engraçado do jornalista: "Onde fica o refrão, o que está acontecendo? Muito ruim!", ressalta, terminando a nota com um último sobe som dos dois atletas cantando.

O texto, informal, abusa da ironia e de expressões coloquiais nada frequentes no jornalismo como "misericórdia" e "pelo amor de Deus". Intercalados com os trechos em que os jogadores citados aparecem cantando, os offs não apenas "casam" com as imagens como as potencializam. A matéria usa uma fórmula para provocar o riso: a exibição de profissionais de uma área (jogadores de futebol) exercendo uma atividade da qual eles não têm domínio (cantar). Para deixar a situação ainda mais inusitada, os personagens são atletas com forte identificação com o público - Richarlyson, Ronaldo, Hernanes, Neymar e Ganso. O resultado é um humor leve, acessível a todos telespectadores - até mesmo a quem não gosta de esporte e não costuma acompanhar os programas sobre o assunto pode se interessar e, inclusive, rir diante da televisão. É o "engraçadismo" sendo utilizado como um recurso para atrair a audiência do público que não tem o hábito de acompanhar as informações esportivas.

No Globo Esporte gaúcho, ao contrário do paulista, predominou a categoria Jornalismo, representada por reportagens como a que abordou a passagem do time
10- É uma marcação técnica no script do programa que indica quando o som do apresentador deve ser substituído pelo som do VT que está sendo rodado (PATERNOSTRO, 1999).

11- Show musical (tradução livre). 
12-Background, ou BG, é o ruído do ambiente ou a música que acompanha o off (PATERNOSTRO, 1999).

13- Neste trecho o repórter faz uma referência à epidemia de dengue registrada nos primeiros meses de 2012 em todo o Brasil. "Entre a dengue e a altitude" é uma referência ao fato de o time ter levado para La Paz um estoque extra de repelente para mosquitos. Épossível afirmar que o repórter tentou fazer uma relação entre a dengue e a altitude como problemas a serem enfrentados pela equipe do Internacional. do Internacional por Santa Cruz de la Sierra para a disputa de uma partida da Taça Libertadores da América. Exibida em 20 de março de 2012, a matéria começa com um ônibus antigo circulando por uma avenida. Com uma música andina de background ${ }^{12}$, o repórter diz: "Ah, a Bolívia. Para o Inter, um lugar de boas recordações". Há um efeito de edição, como o de a imagem de uma televisão sendo ajustada, e aparecem lances de arquivo, de 2011. O jornalista prossegue: "No ano passado, em Cochabamba, goleada sobre o Jorge Wilstermann. Mas para aí: passado é passado...”. Novo efeito de edição e o repórter lê o terceiro off: “...e presente é presente.

$O$ Inter entre a dengue, por isso o estoque extra de repelente para mosquito, $\mathrm{e}$ a altitude ${ }^{13}$. Este oásis em Santa Cruz de la Sierra, com direito à trilha sonora.... Pausa e música ao fundo.

[Continuação da frase anterior]... serve de concentração. E apenas para escapar dos efeitos precoces da altitude de La Paz, o local do jogo. Se todos estão preocupados, imagina ele, o mais experiente. [Imagem do jogador Índio concedendo entrevistas a jornalistas de rádio no saguão do hotel]. Ainda bem que, aos 37 anos, o Índio, único remanescente do título mundial, parece ter um tubo de oxigênio próprio.

Essa é a deixa para a inserção de um trecho da entrevista do zagueiro Índio na qual ele afirma que, apesar da idade, o seu "tubo de oxigênio próprio" ainda está em funcionamento. Depois da fala do atleta, o repórter retorna com a passagem gravada na mesma rua em que foi captada a imagem do ônibus antigo que abriu a reportagem. "Quem dera se o Internacional pudesse falar apenas de Libertadores, da altitude... mas o caso Jô, hein? No mínimo, causou um desconforto no clube", ressalta. A próxima imagem enquadra o diretor de futebol concedendo entrevistas. "Era bem mais fácil jogar, né (sic) Fernandão? $\mathrm{O}$ agora diretor do Inter teve que falar sobre o sumiço do atacante. Jô participou de parte do último treino em Porto Alegre, quando saiu antes, com a alegação de que teria se sentido mal". Na sequência, é inserido um trecho da entrevista do dirigente. Fernandão garante que irá procurar mais informações sobre o fato. Então, o repórter completa: "Hoje, mais um ingrediente na polêmica. Vizinhos reclamaram do barulho nas festas na casa do jogador. Até a Brigada Militar foi chamada [entra uma foto em que o jogador aparece conversando com policiais]".

Com uma música que lembra cantos de torcida em BG e uma imagem da arquibancada lotada no estádio do Inter, o repórter retorna a Santa Cruz de la Sierra. "Bom, mas, para o torcedor, nada de crise. Não tem Jô, tem Jajá. E como eu já disse, a Bolívia é motivo de boas recordações", argumenta o jornalista. No fechamento da matéria, a câmera segue Índio deixando o saguão do hotel e seguindo pra o quarto, rindo e olhando para trás. No último off, um trocadilho com a imagem: "Eles confiam que ainda vão olhar para trás e rir disso tudo".

Mesmo enquadrada na categoria Jornalismo, a reportagem não segue os princípios básicos da profissão. Falta clareza, falta informação. Ela cita muitos aspectos e se detém em apenas dois - a questão da altitude e o sumiço do atacante Jô. Não explica a dengue e a necessidade do uso de repelentes e, embora desenvolva o tema da altitude, sequer informa acima de quantos metros do nível do mar os jogadores vão atuar. Além disso, a sequência de imagens não é organizada de modo a facilitar a compreensão dos telespectadores: 
se passa do ônibus circulando pelas ruas da Bolívia aos lances de partidas, repelente contra mosquitos e, finalmente, à entrevista do jogador Índio. Os efeitos de edição, como a música andina em BG, não apenas contribuem para a confusão como podem desviar a atenção do que está sendo dito e são, também, elementos que expressam o "engraçadismo" que marca o tom dessa matéria.

No último off, por exemplo, é a força da imagem que determina o texto do repórter - mesmo que as palavras não façam nenhum sentido quando consideradas no contexto da reportagem. "Eles confiam que ainda vão olhar para trás e rir disso tudo", é o que afirma o repórter. Não é possível compreender do quê, exatamente, os jogadores poderão rir. Do caso Jô? Dos efeitos de uma altitude que sequer foi informada? Da necessidade (que não foi esclarecida na matéria) de se aplicar repelentes contra os mosquitos? Da partida que será disputada contra um adversário que sequer foi citado? Não há como o telespectador descobrir.

\section{Considerações Finais}

O primeiro objetivo deste artigo, mensurar a predominância dos conteúdos de futebol em relação aos de outros esportes, foi atingido. Por meio da organização de um corpus, confirmou-se a prevalência dos conteúdos relacionados a essa modalidade esportiva em detrimento das demais. A segunda meta desta pesquisa era evi- denciar a utilização do "engraçadismo" no tratamento das informações esportivas - o que também foi cumprido. A partir do estabelecimento das categorias Jornalismo e Infoentretenimento foi possível visualizar a presença de elementos do engraçadismo tanto nos conteúdos classificados como Jornalismo quanto naqueles enquadrados como Infoentretenimento. O terceiro e último objetivo deste artigo era discutir se o amplo espaço destinado ao futebol é resultado da aplicação de critérios jornalísticos ou se é fruto da pressão por bons números de audiência.

Os dados apresentados neste estudo levam a crer que a opção por privilegiar o futebol é mais uma questão de audiência do que propriamente de aplicação de critérios jornalísticos. A nota coberta sobre o karaokê dos jogadores do Santos, por exemplo, não apresenta nenhum valor-notícia além do entretenimento. A passagem do Internacional por Santa Cruz de la Sierra, por sua vez, apresenta valores-notícia - mas também utiliza recursos do "engraçadismo" para agradar a audiência. É possível dizer, após a análise, que os jornalistas acreditam que uma reportagem clara e objetiva, que não abuse dos efeitos de edição, das trilhas sonoras e dos fatos omnibus, não irá chamar a atenção do telespectador. Conclui-se, portanto, que o processo de futebolização do esporte observado na televisão denota um compromisso com os números da audiência - e não com o jornalismo esportivo.

\section{Referências bibliográficas}

ALCOBA, Antonio. Deporte y Comunicación. Madrid: Dirección General de Deportes de la Comunidad Autónoma de Madrid, 1984. 379 p. 
La Prensa Deportiva. Madrid: Universidad Complutense de Ma-

drid, 1999. 207 p.

BARBEIRO, Heródoto; RANGEL, Patrícia. Manual do Jornalismo Esportivo. São Paulo: Contexto, 2006. 188 p.

BARDIN, Laurence. Análise de Conteúdo. Lisboa: Edições 70, 1977. 226 p.

BERNAL, Aurora Labio. Periodismo Deportivo y Sensacionalismo: Motivos para la Reflexión. In: MONTÍN, Joaquín Marín (Org). Imagen, Comunicación y Deporte: Una Aproximación Teórica. Madrid: Vision Libros, 2008. 277 p.

BUCCI, Eugênio. Sobre Ética e Imprensa. São Paulo: Companhia das Letras, 2000. 249 p.

BOURDIEU, Pierre. Sobre a Televisão. Rio de Janeiro: Zahar, 1997, 143 p.

COPA DO MUNDO ELEVA VENDAS DE TV EM 60\%. Meio e Mensagem. 13 jun 2014. Disponível em: <http://www.meioemensagem.com.br/home/marketing/noticias/2014/06/13/

Copa-do-Mundo-eleva-vendas-de-TV-em-60-por-cento.html>. Acesso em: 24 ago 2014.

CHAPARRO, Carlos. Interesse público não se confunde com “interesse do público”. Publicado em: 31 jul 2012. Disponível em: <http://www.oxisdaquestao.com.br/admin/arquivos/artigos/2012_7_31_14_31_7_54154.pdf>. Acesso em: 16 ago 2014.

COELHO, Paulo Vinicius. Jornalismo Esportivo. São Paulo: Contexto, 2008. 120 p.

ERBOLATO, Mário L. Jornalismo Especializado. São Paulo: Atlas, 1981. 158 p.

FERRÉS, Joan. Televisão Subliminar: Socializando através de Comunicações Despercebidas. Porto Alegre: Artmed, 1998. 288 p.

GOMES, Itânia Maria Mota. Tendências do Telejornalismo Brasileiro no Início do Século XXI: Telejornalismo Popular e Infotainment. In: FILHO, João Freire; BORGES, Gabriela (Org). Estudos de Televisão: Diálogos Brasil-Portugal. Porto Alegre: Sulina, 2011. 407 p.

GRAÇA, Ary; KASZNAR, Istvan. A Indústria do Esporte no Brasil - Economia, PIB, Empregos e Evolução Dinâmica. São Paulo: M. Books, 2012. 283 p.

INSTITUTO BRASILEIRO DE OPINIÃO PÚBLICA E ESTATÍSTICA. Esporte Clube Ibope Media 2011. Disponível em: <http://www.ibope.com/maximidia2011/>. Acesso em: maio 2012.

LORA, Manuel Garrido. Violencia y sensacionalismo en la comunicación deportiva. In: MONTÍN, Joaquín Marín (Org). Imagen, Comunicación y Deporte: Una Aproximación Teórica. Madrid: Vision Libros, 2008. 277 p.

OSELAME, Mariana Corsetti. Fim da Notícia: o Engraçadismo no Campo do Jornalismo Esportivo de Televisão. 2013. 153 f. Dissertação (Mestrado em Comunicação Social) - Programa de Pós-Graduação em Comunicação Social da Pontifícia Universidade Católica do Rio Grande do Sul, 2013.

PATERNOSTRO, Vera Íris. O Texto na TV. Rio de Janeiro: Campus, 1999. 158 p.

PATIAS, Jaime Carlos. O Espetáculo no Telejornal Sensacionalista. In: COELHO, Cláudio Novaes Pinto; CASTRO, Valdir José de (Org). Comunicação e Sociedade do Espetáculo. São Paulo: Paulus, 2006. 211 p. 
PLURI CONSULTORIA. O PIB do Esporte Brasileiro. 2012. Disponível em: <http:// www.pluriconsultoria.com.br/uploads/relatorios/PIB\%20Esporte.pdf $>$. Acesso em: nov. 2012.

RANGEL, Patrícia. Globo Esporte SP: Ousadia e Experimentalismo na Produção da Informação-Entretenimento. Videre Futura, São Paulo, 2010. Disponível em: <www. viderefutura.riobrancofac.edu.br>. Acesso em: jan. 2011.

REDE BRASIL SUL. Globo Esporte. Porto Alegre: RBS, 13, 20 e 27 de março de 2012, 3 de abril de 2012. Programa de televisão de jornalismo esportivo.

TRAQUINA, Nelson. Teorias do Jornalismo: a tribo jornalística, uma comunidade interpretativa transnacional. Florianópolis: Insular, 2008. 216 p.

TV GLOBO SÃO PAULO. Globo Esporte. São Paulo: TV Globo São Paulo, 13, 20 e 27 de março de 2012, 3 de abril de 2012. Programa de televisão de jornalismo esportivo. TVS CELEBRAM AUDIËNCIA DA COPA. Meio e Mensagem, 18 de julho de 2014. Disponível em: <http://www.meioemensagem.com.br/home/midia/noticias/2014/07/18/ TVs-celebram-audiencia-da-Copa.html>. Acesso em: 16 ago 2014.

WOLF, Mauro. Teorias da Comunicação. Lisboa: Editorial Presença, 1985. 247 p.

Estudos em Jornalismo e Mídia está sob a Licença Creative Commons 2.5 